\title{
"The love in the room": Evaluating the National Year of Reading in an Australian public library
}

Sue Reynolds, Bernadette Welch

\begin{abstract}
This study was influenced by research into the impact of the UK National Year of Reading in 2008 using the Generic Social Outcome Framework from the Museums, Libraries and Archives Council. In 2012 a National Year of Reading was held in Australia which offered another opportunity to investigate the nature of impact. While formal evaluation processes were put into place at the national level, our study was a small-scale qualitative research project which considered the evaluation of impact related to National Year of Reading activities at one urban public library service. Data collected included focus group interviews with library staff, as well as desk data from the library service. The findings suggest that it is necessary to give due consideration to impact measures and collection of appropriate data at the planning stages in order to evaluate impact effectively. Measuring impact is much more difficult but ultimately more worthwhile than that of measuring output. The evaluation of impact is an important tool in strategic planning and advocacy and new ways of measurement need to be incorporated into planning and management.
\end{abstract}

\section{Introduction}

Rankin, Brock and Matthews (2009) posed the question "Why can't every year be a National Year of Reading?" as the conclusion to their evaluation of the impact of the United Kingdom's 2008 National Year of Reading (NYR) in Yorkshire. This is a rhetorical question because for libraries everywhere and of every type, reading - promoting, enhancing, facilitating and deploying it - is part of what

\section{Author}

Sue Reynolds is a researcher and lecturer in information management at RMIT University, Melbourne, Australia. Her principal research is in current and historical library practice.

Email: sue.reynolds@rmit.edu.au

Bernadette Welch is a lecturer in information management at RMIT University, Melbourne, Australia. Her areas of research include information provision and reading for young people. 
they and their clients do every day, every year, regardless of other mandates and imperatives. The research reported here does not replicate the UK project but is a direct result of Rankin's message to Australian researchers that "there's only one year of reading, don't waste the opportunity".

Despite the general focus by libraries on reading, and their advocacy for information literacy (American Library Association, 2013; Australian Library and Information Association, 2006; Chartered Institute of Library and Information Professionals, 2013), literacy rates continue to be a concern around the world (UNESCO Institute for Statistics, 2012; Central Intelligence Agency, 2013), including in Australia (Australian Bureau of Statistics, 2013). In 2012 the National Year of Reading in Australia had the improvement of literacy at its core and was designed to capitalise on, enhance and add extra inspiration to activities already existing around books, reading and literacy. The NYR campaign was conducted under the auspices of the Australian Library and Information Association (ALIA) and directed by the Library Agency.

The year was officially evaluated by researchers from the Centre for Research in Early Childhood at Edith Cowan University funded by the Office for the Arts, Department of Regional Australia, Local Government, Arts and Sport (BarrattPugh, Smith and Anderson, 2013). Four examples, one national and three at state or territory level, were used in the official evaluation to represent nationwide involvement in the NYR and the overall response to the opportunities for libraries, and others, presented by the year.

The Australian NYR Snapshot reports that there were " 4,000 events, 12,000 online followers, 200,000 participants; $\$ 1.7$ million funding, \$5.6 million in kind support, \$26 million media coverage, $\$ 20$ return for every $\$ 1$ invested" (Love2read, n.d. a). But now that the posters have been taken down, the touring exhibition over and the resident authors and poets departed, what is left apart from the glow of a successful year and some impressive statistics?

\section{Methodology}

This paper reports a small-scale qualitative research project which considered the evaluation of the National Year of Reading in Australia in 2012 within a large public library service in a major Australian city. A wide range of programs and activities was considered as viewed by staff directly involved with their design and delivery during the NYR. Data was collected from multiple participants from two different branch libraries through the conduct of semi-structured focus groups during 2012. Further data (for example, door counts) was provided by the participating library service. Focus group participants were identified by branch library managers and then invited to be involved in the research. Three focus groups were conducted in order to consider the views of library staff involved with local NYR planning and activities: one early in the NYR, and two other interviews towards the end of the year. Each focus group was made up of different participants from three branch libraries. Focus group participation depended on the level of involvement with NYR relevant to the time of the scheduled focus group; there were seven participants in total. Ethics approval was sought and 
granted by the RMIT University College of Business Human Ethics Advisory Network prior to the commencement of the research project.

Analysis of the data is directly linked to the themes of the national evaluation of the NYR, and provided in this research as part of a narrative summary. The researchers have used the selected library service as the basis for reflecting on how the NYR was evaluated in one library service. Evaluation of the library was considered in relation to the general aims of the NYR in Australia and in comparison with the findings of the NYR evaluation project conducted with a national focus. The library service's own aims for the year are also considered. The objectives of this research project were to:

- Consider the outcomes of NYR activities in one library service;

- Compare the outcomes of the library service under consideration with the conclusions determined by the national NYR evaluation project;

- Consider currently available impact evaluation techniques/strategies for their usefulness in the library service being investigated and library service evaluation generally.

\subsection{Research and focus group questions}

The research questions and consequent questions for the focus groups were developed using the conclusions reached by the national evaluation of the National Year of Reading as a framework. These conclusions are given later in this paper but the research questions were:

1. Did the national NYR framework support local NYR activities?

2. What role did the library play in its community during the NYR?

3. Were partnerships important for success?

4. Were new target audiences involved, as well as existing target audiences?

5. Was evaluation extensive enough?

6. Was funding a significant factor?

Focus group participants were asked the following semi-structured questions:

1. What are you doing to promote the NYR in your library?

2. What opportunities has the NYR framework offered for developing local activities and initiatives?

3. In what ways has the NYR changed the way you are supporting your local community?

4. Were partnerships with other organizations related to the success of local NYR activities?

5. How has the NYR impacted on your work with existing target groups?

6. Did the NYR impact on involvement with new target groups?

7. How useful was any evaluation you made of NYR activities? 
8. Was funding for NYR relevant to its success?

\subsection{Limitations of the research}

Questions relating to national conclusions regarding national communication, bipartisan support and international interest were not included as research questions due to their lack of relevance to the study of the impact of the NYR at a local level.

\section{Measuring impact in libraries}

Measuring impact has always been challenging for social organizations such as libraries. In this accountable age, the quantitative measurement of outputs (for example, loans, visitor statistics) is no longer enough to satisfy funding bodies and governments or to meet on-going planning and advocacy needs. Measurement of impact is seen as a viable method to evidence the contribution of libraries to their communities and to measure the development of their social capital (Markless and Streatfield, 2013). Impact measures can also be used to demonstrate how a specific program or activity has been valued by stakeholders. Impact evaluation is differentiated from the "Input, process, output model" of evaluation where inputs are resources required for a process (such as an activity or program), to produce an output, usually measured quantitatively.

In addition to the fact that impact is often intangible and therefore problematic to measure, another of the difficulties in determining how impact might be measured in libraries is in the varied use and meaning of impact. Terms such as "output", "outcome", "impact", "benefit" and "value" are often used in similar ways (Poll, 2012, 123). Hosseini-Ara and Jones (2013) assert that in order to measure impact libraries have to move beyond traditional evaluative methods, which really measure "outputs", to consideration of "outcomes". Markless and Streatfield (2013), in their seminal text Evaluating the impact of your library, prefer to use the term "impact" rather than "outcomes" where impact is the combined effect of inputs, processes and outputs on an individual or group and is measured qualitatively (Markless and Streatfield, 2013).Rooney-Browne, in her extensive discussion of both qualitative and quantitative methods for the measurement of the value of public libraries in the UK, encourages the determination of "common measures, language and practices for collecting and analysing data" (RooneyBrowne, 2011, 39).

One of the aims of an international standard for impact assessment, Methods and procedures for assessing the impact of libraries, (ISO/DIS 16439, under discussion, 2013) is to "standardise the terminology and the definitions for impact assessment" (Poll, 2012, 122). Creaser and Spezi $(2013,32)$ discuss the difficulties of using an outcome-based approach, "seen ... as a good proxy for impact". They differentiate between "input/output based", "hybrid" and "outcomes based" measures for public libraries and present a selection of tools which could be used for each method.

Markless and Streatfield (2013) have produced a model which differentiates between "service performance measurement" - assessed in terms of performance data - and "impact on people" - evaluated by designing and collecting impact 
indicators as evidence. They stress the need to determine the aims and objectives of what is being considered in terms of impact, and establishing appropriate impact indicators related to these, before planning the activities to be evaluated.

They warn that libraries often start with activities rather than objectives and that it is necessary to "put the impact back into planning" in order to:

Generate impact indicators that will drive your data collection in areas that will provide you with the elusive evidence of impact that is vital to decision making and real service development.

(Markless and Streatfield, 2013, 63)

\subsection{Frameworks for measuring impact}

In 2008 the UK Department for Culture, Media and Sport (DCMS) commissioned a study of how the impact of library services was measured. The report pointed to the fact that most evaluations were of individual activities, not able to be measured in terms of change over time (BOP Consulting, 2009, 2). The Generic Social Outcomes (GSOs) were developed by the Museums, Libraries and Archives Council (abolished in 2012) as a tool to gather evidence and measure the impact of libraries and other cultural institutions. Rankin, Brock and Matthews (2009) used the GSOs to develop a theoretical framework for analysing the impact of the UK NYR on organisations in Yorkshire based on the three main strands of "Stronger and safer communities", "Health and wellbeing" and "Strengthening public life" (Museums, Libraries and Archives Council, 2008).

These strands can immediately be recognised as relevant to the Australian Library and Information Association's assertion that libraries "build safer, stronger, sustainable communities and contribute to our fair and open Australian way of life" (Australian Library and Information Association, 2011, 5). However, in Australia the measurement of impact, as described by Markless and Streatfield (2013), is yet to be addressed, with most measures of the value of libraries, particularly public libraries, being considered in economic terms (Library Council of New South Wales, 2008; SGS Economics and Planning, 2011; SGS Economics and Planning, 2013; State Library of Queensland, 2012).

The international standard under discussion for "assessing the impact of libraries" (ISO/DIS 16439 (2013)) offers promise for evaluating impact. The draft standard refers to the impact of libraries in terms of influence on people as individuals or collectively. This is similar to the definition of "impact" provided by Markless and Streatfield (2013) as being an effect on an individual or group to produce an outcome. The draft standard describes a sequential model for moving beyond impact to value, where the value of libraries is considered with regard to stakeholders (funding bodies, the government, the public). Library impact is considered in relation to individuals (including library staff), the library itself or its community and social impact; economic value is also considered. The draft international standard emphasises the stages in the model designed by Markless and Streatfield (2013), starting with the library's mission, goals and objectives and directly relating them to the desired impact on the library's community and on society. The draft standard also provides detailed descriptions of methods which 
can be used by libraries in different sectors to assess impact for planning and promotion, longitudinally, and between libraries, and to underpin political decisions related to libraries.

\section{Overview of the National Year of Reading and its evaluation}

The rationale for the Australian NYR was the desire to address the apparent low literacy levels in Australia for people of all ages, children to adults. This desire is reflected in the aims of the National Year of Reading:

- For all Australians to understand the benefits of reading as a life skill and a catalyst for wellbeing;

- To promote a reading culture in every home;

- To establish the aspirational goal for parents and caregivers to share books with their children every day.

(Barratt-Pugh, Smith and Anderson, 2013, 8)

The NYR was also to provide "the opportunity to change attitudes and behaviours, and embed a reading culture to benefit current and future generations" (Love2read, n.d. b, 2). This is clearly a statement related to consideration of the impact of the year on the Australian population.

In order to address the stated aims, the NYR implementation strategy was designed as a flat-topped pyramidal structure with four national campaigns as the capstone, state and territory organised events and activities immediately underneath this, and many more events and activities conducted at a local level at the base.

This framework enabled the generation of support and momentum at a national level, while devolving ownership of local initiatives to the "grass roots' level".

(Barratt-Pugh, Smith and Anderson, 2013, 3)

Additional to this structural underpinning was a variety of partnerships, either formally established with founder partners, ambassadors and friends, again at national and state or territory level, or locally determined.

\subsection{National evaluation of the NYR}

The national evaluation of the Australian NYR, conducted by the Centre for Research in Early Childhood Education, Edith Cowan University, Western Australia was based on three questions:

1. What is [sic] the nature and outcomes of National Year of Reading partnerships at a national, state, program and event level in relation to the promotion of the importance of reading as a life skill, the importance of a reading culture in the home, and the importance of sharing books with children from birth?

2. How has involvement in the National Year of Reading added value to the outcomes within and between participating organizations that are normally achieved in a year? 
3. How will the partnerships and programs be sustained and developed beyond 2012 ?

(Barratt-Pugh, Smith and Anderson, 2013)

Using a qualitative case study approach the national evaluation aimed to explore "the nature, impact and sustainability of the National Year of Reading" (BarrattPugh, Smith and Anderson, 2013, 3) and to synthesise the findings in relation to the questions posed above (Barratt-Pugh, Smith and Anderson, 2013, 3). The questions asked for the national evaluation of the NYR in Australia and its aims refer to "impact", "value" and "outcomes" yet the conclusions reached by the evaluation do not address these measures. The conclusions, written in terms of what was achieved were based on process and administration successes. This stance supports the contention that there is confusion over the use of these terms.

The conclusions reached were that:

- The national framework was central to success;

- Libraries were at the heart of NYR;

- Partnerships were crucial;

- Key messages were delivered to both new and target audiences;

- Evaluation needed to be extended;

- National communications were important for partnerships;

- Funding was a significant factor;

- Bi-partisan support was important for the future of the NYR;

- Interest from other countries was generated.

\subsection{NYR and its effect on the library service under consideration}

The library service used for this research consists of four physical library branches in urban communities. The main branch library is the busiest public lending library in the state in which it is located. The library service provides spaces, resources, services and activities for target groups which, according to its website, include the unemployed, homeless, age groups from infants to older people, community groups, the staff of the wider local government agency to which it belongs, housebound, low-literacy clients, researchers and students, people with disabilities, culturally and linguistically diverse (CALD) groups and local community groups.

The library service's specific aims during the NYR, also addressed in this paper, were to:

- Increase membership;

- Increase loans;

- Capture qualitative feedback; 
- Assess the reach to target groups and disadvantaged groups which do not normally use libraries.

Prior to the commencement of the NYR, the library service under consideration here had a number of meetings (described as "copious" by a focus group participant) to plan activities for the year but the issue of qualitative evaluation was not addressed. The discussions were around how to make what was already being done fit the NYR imperative and then be developed to accommodate new activities and events. This process was pragmatic and employed the "joined up approach" advocated by the national NYR strategy (Love2read, 2012, 2). As one staff member said:

We didn't really have a clue to start with ... we're all really busy and we've got a lot on already so we don't want to take on extra things. [We considered] what are we already doing that we can tweak to fit? ... and then we did actually start doing new activities.

More than one focus group member described the year's activities as a "ramping up" of the usual events and activities, "a bit of an injection ... a fresh approach"; one research participant said the year "gave us a push ... to find things"; another that it made staff "think creatively about how we can do things". In support of the contention of the national evaluation report that the NYR provided a national framework for local activities (Barratt-Pugh, Smith and Anderson, 2013, 2), a focus group participant said that the NYR promoted the idea of "Think globally, act locally".

The library service produced a calendar of NYR events which commenced with the national launch and included the national campaigns. All of the events held during the year were conducted under the banner and branding of the NYR and were divided by age - for adults, youth and children. Some were activities which opportunistically fitted into the year, for example the open day for a new branch library; some were regular activities "tweaked to fit" the year, such as the annual Premier's Reading Challenge and National Simultaneous Story Time; but an analysis of the calendar of events indicated that most were specially conceived for the NYR calendar.

Special events convened for the NYR by branches of the library service included the promotion of no fines for junior and young adult material during school holidays, a poet in residence, an OI! (Online information) Resource Challenge, the renaming of a city lane and a series of Rebound Books craft activities. Rebound Books charged a fee for participation and proceeds were donated to the Indigenous Literacy Foundation (ILF), an organisation which was an official NYR partner.

A focus group participant concluded that during 2012 the endeavours of the NYR were pervasive and omnipresent:

It's in your head, every week you're reminded ... you couldn't escape it really ... and it did result in bigger things than we usually do. 


\subsection{A comparison of local and national evaluations}

The conclusions of the national evaluation (Barratt-Pugh, Smith and Anderson, 2013) are given below. They are discussed in relation to what happened at the library service under consideration in this research as discerned by asking relevant questions in the focus group sessions. Evidence in relation to each question from the focus group interviews is provided.

\subsubsection{The national framework was central to success}

In relation to this national finding focus group participants were asked to consider: Did the national NYR framework support local NYR activities?

It was clear from the discussions in the focus groups that many activities run during 2012 would have been offered regardless of the National Year of Reading. However, the national framework did provide a focus for the library's 2012 calendar of activities. According to a focus group participant the NYR gave a framework to "hang development off within the library" and this was valued by library staff. Additionally, its "Love2read" green and purple flower logo provided very recognisable branding used by libraries during the year (Love2read, 2013), with each petal representing the reading themes of feel, escape, laugh, cry, discover, think, dream, explore, question, grow. These themes were used by the library service to inspire reading lists selected by council staff each month in an activity related to the national campaign to bring the NYR to workplaces. Each list of titles was linked to the catalogue reserve system and this resulted in an apparently related spike in borrowing of the titles recommended. In addition focus group participants considered that the national approach created a "healthy competition between libraries" and was "energising", acting as "a bit of an injection [for] a fresh approach".

It was generally felt that the national framework helped by providing materials and branding and "raising our profile nationally in the work of libraries and books and reading across the country". The branding has been considered so successful nationally that it is continuing to be used by Love2read into 2013 "making the most of the momentum that had been created during the National Year of Reading" (Love2read, 2013).

\subsubsection{Libraries were at the heart of the development, delivery and success}

To address this question, focus group participants were asked to consider: What role did the library play in its community during the NYR?

It was considered by the focus group members that the NYR badging reminded people, including staff of the library, that the basis for what the library does is founded on books and reading - "this is what we do". One focus group participant believes that the library is considered to be "all things to all people ... a lounge room ... a study ... a careers centre", but these roles were rendered more visible during the NYR, whilst also reminding people of the library's traditional core business related to books and reading. 


\subsubsection{Partnerships were crucial}

For the focus group participants were asked to consider the question: Were partnerships important for success?

The dual nature of the partnership of the city's Lord Mayor with both the NYR nationally, as an official ambassador, and the city at a local level, was considered particularly important. The mayor's involvement at the national level as an official NYR ambassador raised the profile of the library within the city. As a former teacher of English literature, he was considered by a focus group participant to be the "perfect" ambassador to assist in countering the perception that "libraries are not really viewed as all that important ... just a library". The crucial role played by the mayor was summed up during a focus group, very pragmatically, as being vital because "It's very important that we're on the radar ... particularly for funding".

An additional partnership with a neighbourhood centre was established during the NYR and the library will continue with this particular partnership because the children involved "need to learn to read for both pleasure and literacy".

\subsubsection{New and target audiences were reached}

This national finding was framed for the focus group participants in terms of questions related to: Were new target audiences involved, as well as existing target audiences?

During the NYR the library continued to service the groups listed on its website but these groups were specially "targeted for the year", with new activities developed for them as part of the NYR activities. New groups and individuals targeted during NYR and encouraged to visit a branch library included those new to the community and transient visitors, and people considered alone within it.

The poet in residence activity was aimed at attracting new people from different cultures, both male and female; aged-care groups came to talk about what reading meant to them and about books they loved; a homework group was established for NESB (non-English speaking background) children; new mothers who had not yet attended a regular session for infants, toddlers or pre-schoolers were targeted; and a group of recently released prisoners participated in a "Get back to life" program. School groups from all over the state visited the library for an exhibition of original illustrations from Are we there yet? a children's picture story book by Alison Lester which was an on-going part of the NYR activities.

There was mixed success with the activities designed for these identified groups. It was reported in a focus group that the response to the poet was "quite incredible" and life changing for some of the participants. This year-long program was very labour intensive (booking rooms, marketing, co-ordinating etc.) but "it was such an amazing success" that it was worth it. Focus group members involved with this NYR activity were excited by the program and by "the love in the room [which] was extraordinary". They believed that "It gave a lot to a small group of people... who will benefit from this in a massive way". The aged-care reading circle, as a supplement to the regular seniors group, was described as "one of the most energising things ... all year ... it was incredible". On the other hand, the 
recently-released prisoners group was not very successful due, it was felt, to their inexperience with books while in prison; and the new mothers' activity was very poorly attended, possibly due to inappropriate timing causing a clash with other activities.

Nonetheless, the library intends to persist with some of the unsuccessful projects aimed at new target groups, for example NESB children, and prisoners. These two target groups are particularly important in view of the NYR's aim to address poor literacy rates in Australia and the local library's own NYR aim to reach "disadvantaged groups which do not normally use libraries". A focus group participant articulated the reason for pursuing activities for these and other groups: "we're not only committed ... we want to support [them]".

\subsubsection{Evaluation needed to be extended}

This finding from the overall evaluation of the NYR was definitely significant for the library in this research and the focus group participants were asked to consider: Was evaluation extensive enough?

The answer to this question is that generally there was no qualitative evaluation made of either individual events or of the NYR overall. Library staff admitted that, in fact, they had merely collected a few feedback sheets (for one event only) and produced a very brief "highlights" report aimed at sharing what had occurred during the year in terms of events and activities held, together with some output measures such as the number of attendees. This report was described as "Fairly brief ... so it could be shared. But that's it". Nonetheless, focus group participants considered that the NYR acted as a "good shop window to promote services that we do all the time", and the highlights report was able "to say look at ... what we did, look at what we can do".

There was no detailed formal reviewing of the year and generally feedback was "conversational rather than on paper... over a long coffee". The reasons given for this was that "it didn't work", "ticked boxes tell you nothing", "it's hard to do" and "it just really wrecks the whole thing". This last comment was made in relation to the poet in residence program where staff felt that collecting formal evaluations would have interfered with the "vibe" for the "people [who] were just elated by it all" and that "the love in the room" would have been "such a hard thing to actually measure or put down in words". Staff felt that they could "just tell" if something was successful or not for the client groups targeted by each activity.

The library did collect membership, loans and visitor statistics for 2010, 2011 and 2012 as recommended by the national NYR agenda, and to meet the library's local NYR aims to increase membership and loans. The figures for new members, loans and visitors for each year 2010, 2011 and 2012 (the NYR) are shown in Table 1.

\begin{tabular}{|l|l|l|l|}
\hline Year & New members & Loans & Library visits (Door count) \\
\hline $2010-2011$ & 17,417 & $1,257,872$ & 997,810 \\
\hline $2011-2012$ & 19,600 & $1,302,166$ & $1,035,399$ \\
\hline
\end{tabular}




\begin{tabular}{|l|l|l|l|}
\hline $2012-2013$ & 31,409 & $1,321,383$ & $1,105,276$ \\
\hline
\end{tabular}

\section{Table 1: Library statistics 2010-2013.}

The difference in new member numbers from 2010 to the end of the National Year of Reading in 2012 is substantial, but attribution for the increase is difficult to ascribe definitively to the NYR without further research. One library staff member suggested that the NYR probably did contribute to the upward trend, augmented by both new reader development practices employed by library staff (introduced to support NYR activities) and the redesigning of library spaces. Another member of staff said "Not sure if it would have happened anyway or if the NYR was responsible. Perhaps a little of both?" The same could perhaps be said for increases in loans and library visits over the same time period.

Additional quantitative measures indicated that a "bump" occurred in reserves, related to titles promoted during the year (for example, from booklists compiled from staff recommendations), and there was an increase in local children joining the library once they realised they could use it for book borrowing and not just for playing games.

\subsubsection{Funding was a factor}

In answer to the question "Was funding a significant factor?" it was indicated that no targeted funding was provided in the budget for the NYR related activities. This was not considered to be an inhibiting factor for conducting activities although focus group participants did consider that they were overloaded with tasks and could have done with some dedicated funding for additional staff hours during the year.

\subsection{NYR evaluation specific to the library under consideration}

Qualitative outcomes were not formally considered by the library service being considered in this research; however, some general outcomes were articulated by the focus group participants. The national aim of raising the status of reading appears to have been very successful at the local level - in the library itself, in the local council and for the library's clients - based on the number of participants in activities. The library staff said that:

We thought we were doing good reading things because we were doing the standard reading things - book groups and stuff - but it's made [us] focus on what else it is that the public would like.

The library was particularly pleased with the staff training program developed inhouse and rolled out during the NYR to every staff member in order to improve reader development. The library realised that:

You can't promote your library as being a place where you can come and talk about books if the staff aren't ready.

This training program provided scaffolding for reader services (for example, tips on interacting with patrons) and raised awareness amongst library staff of the importance of books and reading in the library's service. 
The NYR also helped with planning for programs in the year to follow (2013), with a new programs co-ordinator appointed to develop activities across the board, for children, youth and adults. The year taught staff that they had "permission to try and fail" and that:

If it works go with it, if it's feeling like a hard slog... just don't do it... don't put your energy into that.

One person summed up her involvement with activities during the NYR as having made her "feel really proud... because we came up with quite an amazing list of activities".

Problems associated with being involved in the NYR activities also provided learning opportunities for library staff. Problems included: it was labour and time intensive, with too many groups targeted so that it became overwhelming at times; some activities were too large and too varied in demographics, and some were not successful in terms of numbers; promotion was considered to be difficult. These factors in particular mean that some of the events organised for the NYR will not be sustainable into the future. As one participant in the focus group interviews said "We're just finding more on our plate so really it's not sustainable".

Additionally, there was a lot of staff turnover occurring in the library system, not related to NYR, during 2012 and this particularly impacted on the library's ability to focus on the reading programs and, most importantly, on the ability of the library to conduct strategic evaluations of the year's events and activities. This was a regret for library staff members who realised that the lack of formal evaluation was "our downfall because we have no evidence" of the success of our NYR activities.

However, in the end, the library staff involved with this research considered that the NYR had been "not just about generating reading, it's about community". The library found that:

Every time we go out to community consultation, the one thing the community want is a library... it's a wonderful thing because our programs are very much entrenched in that holistic outlook of bringing community together.

One focus group participant considered that:

the bottom line [is] pleasure... National Year of Reading makes us celebrate it a lot more... every year's the National Year of Reading and that's a great thing.

This statement can be used as an affirmative answer to the question posed by Rankin, Brock and Matthews (2009): "Why can't very year be a National Year of Reading?"

\section{Conclusion}

Rankin, Brock and Matthews's $(2009,21)$ evaluation of the UK NYR considered that the "voice and experiences of the practitioner proved to be ... really important". In the current research, the combination of output statistics and the voice of the practitioners did go some way to offering a perspective of the impact of the NYR on the library service being investigated. In participating in this 
research process, staff were offered a chance for reflection which necessitates some consideration of "impact" and can be a beginning for this process.

The library staff who participated in the focus groups indicated that there was little or no formal evaluation of the NYR activities but their reflections on the year articulated what they valued, enjoyed, and benefited from during the year, and what was difficult and unsuccessful. Generally, they considered the year to be successful in terms of the activities delivered and their own learning but they also admitted that they had no hard evidence of this. Feeling the "love in the room" is not a measurement of impact.

Ellard, Kelly and McKerracher $(2012,263)$ suggest that the "success of the [NYR] can be judged through the media results, the partnerships developed and the in-kind support received" and that the lasting legacy is "the attention libraries received from the highest levels of government". These successes are all metricbased measurements reflecting an input, process, output model rather than consideration of impact on people or society and it remains to be seen if there is in fact a lasting legacy. Neither impact nor value can be determined without evaluating the outcomes for participants in the programs and activities of the NYR (including library staff) and then considering the effect of these outcomes in terms of impact, using impact measures such as those suggested by the UK GSOs or the ISO standard (when it is released).

The national evaluation of the NYR asserts that the year has:

Placed libraries and library strategies at the heart of current social development programs, aligned with the current government educational targets... and uniting community groups around a core social necessity.

(Barratt-Pugh, Smith, and Anderson, 2013, 83)

Now is the time to take this foundation and plan for future activities with impact measures embedded in the plan. As the evaluation document states "a year is not enough" (Barratt-Pugh, Smith and Anderson, 2013, 90); it is recommended that "evaluation should be built into every continuing initiative" (Barratt-Pugh, Smith and Anderson, 2013, 90). The type of evaluation needed, if a measure of impact is required, should be carefully considered before each "continuing initiative" is reenacted.

Both the UK GSOs and the new ISO standard could be used to achieve the necessary evaluation if the relevant model and framework are implemented in the planning process. One participant in the focus group interviews said that, in relation to the NYR, "It's hopefully not just going to drop... certainly there'd be a current to continue". But it is only worth continuing if there really is an impact that is discernible and valuable to the stakeholders and of social value to the library community.

The "elusive" (Markless and Streatfield, 2013, 63) aspect of measuring impact offers the biggest challenge to libraries trying to justify their programs and activities - for recognition, funding and sustainability. Additionally, Creaser and Spezi (2013) consider that one of the main issues with measuring impact in that it requires labour intensive planning, involving stakeholders in the determination of 
the required social outcomes from the outset and establishing work practices to achieve these. The cost of the implementation process may be prohibitive for libraries in a tough economic environment. Creaser and Spezi (2013) suggest that implementing a hybrid model, incorporating both qualitative and quantitative measures, may act as an interim measure as both libraries and their parent bodies assimilate the value of impact measures.

Australian libraries are yet to seriously address impact measures but they can benefit from the research and discussion which has been underway in the United Kingdom and United States and perhaps look forward to the release of the new International Standard as a common means for defining and measuring impact and value.

\section{References}

American Library Association (2013) Key action areas. URL

http://www.ala.org/aboutala/missionpriorities/keyactionareas [accessed 24.11.13].

Australian Bureau of Statistics (2013) Background characteristics. 4228.0 -

Programme for the International Assessment of Adult Competencies, Australia, 2011-12. URL

http://www.abs.gov.au/ausstats/abs@.nsf/Lookup/4228.0Main+Features20201112 [accessed 24.11.13].

Australian Library and Information Association (2006) Statement on information literacy for all Australians. URL http://www.alia.org.au/about-alia/policiesstandards-and-guidelines/statement-information-literacy-all-australians [accessed 24.11.13].

Australian Library and Information Association (2011) Beyond a quality service: strengthening the social fabric; standards and guidelines for Australian public libraries. Deakin, ACT: ALIA.

Barratt-Pugh, C., Smith, P. and Anderson, K. (2013) What a difference a year made! An evaluation of the National Year of Reading 2012 in Western Australia, Queensland and the Australian Capital Territory. Perth: Centre for Research in Early Childhood, Edith Cowan University.

BOP Consulting (2009) Capturing the impact of libraries. London: Department for Culture, Media and Sport.

Central Intelligence Agency (2013) Literacy, The world factbook. URL https://www.cia.gov/library/publications/the-world-factbook/fields/2103.html [accessed 24.11.13].

Chartered Institute of Library and Information Professionals (2013) Information literacy project: Overview. URL http://www.cilip.org.uk/cilip/advocacy-awardsand-projects/projects-and-reviews/information-literacy-project/information-0 [accessed 24.11.13].

Creaser, C. and Spezi, V. (2013) Quality frameworks for public libraries. CILIP Update October, 32-35. 
Ellard, R., Kelly, P. and McKerracher, S. (2012) National Year of Reading: A year-long celebration and a lasting legacy, Australian Library Journal 61(4), 255263.

Hosseini-Ara, M. and Jones, R. (2013) Overcoming our habits and learning to measure impact, Computers in Libraries 33(5), 3-7. URL http://www.infotoday.com/cilmag/jun13/Hosseini-Ara Jones--Overcoming-OurHabits-and-Learning-to-Measure-Impact.shtml [accessed 24.11.13].

ISO/DIS 16439 (2013) Methods and procedures for assessing the impact of libraries. URL

http://www.iso.org/iso/home/store/catalogue tc/catalogue detail.htm?csnumber= $\underline{56756}$ [accessed 24.11.13].

Library Council of New South Wales (2008) Enriching communities: The value of public libraries in New South Wales. URL

http://www.sl.nsw.gov.au/services/public libraries/docs/enriching communities.p df [accessed 24.11.13].

Love2read (n.d. a) National Year of Reading 2012. URL

http://www.love2read.org.au/NYRreport.pdf [accessed 24.11.13].

Love2read (n.d. b) The National Year of Reading. URL

https://love2read2012.wikispaces.com/file/view/NationalYearofReadingIntroducti on110902.pdf [accessed 24.11.13].

Love2read (2012) National Year of Reading 2012: Briefing paper for participants in the National Year of Reading legacy event, 12 November, 2012. URL

http://love2read2012.wikispaces.com/Legacy+event [accessed 24.11.13].

Love2read (2013) About us. URL http://www.love2read.org.au/about-us.cfm [accessed 24.11.13].

Markless, S. and Streatfield, D (2013) Evaluating the impact of your library. London: Facet.

Museums, Libraries and Archives Council (2008) Generic social outcomes. URL http://www.inspiringlearningforall.gov.uk/toolstemplates/genericsocial/ [accessed 24.11.13].

Poll, Roswitha (2012) Can we quantify the library's influence? Creating an ISO standard for impact assessment. Performance Measurement and Metrics, 13(2), 121-130.

Rankin, C., Brock, A. and Matthews, J. (2009) Why can't every year be a National Year of Reading? An evaluation of the NYR in Yorkshire, Library and Information Research, 33(104), 11-25.

Rooney-Browne, C. (2011) Methods for demonstrating the value of public libraries in the UK: A literature review. Library and Information Research, 35(109), 3-39.

SGS Economics and Planning (2011) Dollars, sense and public libraries: The landmark study of the socio-economic value of Victorian public libraries. URL 
http://www.slv.vic.gov.au/sites/default/files/dollars-sense-public-librariessummary-report_1.pdf [accessed 24.11.13].

SGS Economics and Planning (2013) National welfare and economic contributions of public libraries: Final report, Australian Library and Information Association. URL

http://www.alia.org.au/sites/default/files/Contribution\%20of\%20Australian\%20P ublic\%20Libraries\%20Report.pdf [accessed 24.11.13].

State Library of Queensland (2012) The library divided; Summary report: A guide to the socio-economic value of Queensland's public libraries. URL

http://www.slq.qld.gov.au/_data/assets/pdf_file/0018/226143/the-librarydividend-summary-report.pdf [accessed 24.11.13].

UNESCO Institute for Statistics (2012) The official source of literacy data. URL http://www.uis.unesco.org/Literacy/Pages/default.aspx [accessed 24.11.13].

\section{Acknowledgement}

The authors would like to acknowledge the library service involved in this research and to thank library staff for their time and thoughtful input. Thanks are also due to Carolynn Rankin for drawing attention to the research conducted in the United Kingdom and for the potential of similar research in Australia.

\section{Open access and copyright}

Library and Information Research is an open access journal. A freely available copy of this paper may be downloaded from the journal's website:

http://www.lirgjournal.org.uk.

Copyright and associated moral rights in works published in Library and Information Research are retained by the author(s) but this paper may be used freely, with proper attribution, in educational and other non-commercial settings. 